I Universidade do Estado do Rio de Janeiro (Uerj), Instituto de Estudos Sociais e

Políticos (Iesp), Rio de Janeiro, RJ, Brasil

frederic@iesp.uerj.br

Frédéric Vandenberghe'

\title{
A RELAÇÃO COMO OPERADOR MÁGICO. SUPERANDO A DIVISÃO ENTRE SOCIOLOGIA PROCESSUAL E RELACIONAL' ${ }^{1}$
}

O tempo das grandes sínteses teóricas acabou. Em vez de uma teoria social compreensiva com ambições universais, temos agora uma variedade de novas abordagens sensibilizantes, tais como a sociologia analítica, a sociologia pragmática, a sociologia cultural, a sociologia moral, a sociologia pública e, enfim, também a sociologia relacional, que discutirei neste artigo. Em comparação com o "novo movimento teórico" dos anos I980 (Alexander, I987), os novíssimos movimentos teóricos são mais profissionais e também mais modestos. Diferentemente de Luhmann ou Bourdieu, por exemplo, os novos teóricos não acreditam que possam conceitualizar o mundo inteiro, incluindo autorreflexivamente eles mesmos, seus componentes e seus oponentes em suas próprias superteorias. Diferentemente de Habermas, eles não propõem um grandioso panorama da tradição filosófica e uma síntese metateórica das teorias sociais existentes com a intenção de diagnosticar o presente. Antes, mais modestamente, apresentam uma perspectiva, um paradigma, um modo de aglutinar abordagens em competição em torno de uma nova abordagem, conceito ou tema. De forma característica, eles concebem suas construções não como teorias grandiosas (grand theories), mas como um conjunto de teorias coordenadas de médio alcance capazes de lançar nova luz sobre uma variedade de temas e fundir-se em um quadro conceitual provisório, mas passível de expansão. Isolada, nenhuma das teorias pode criar um efeito de arrastamento; juntas, porém, por meio da articulação de conceitos, de coordenação de redes 
e publicação de livros e revistas, elas podem eventualmente levar à emergência de um movimento acadêmico. Seguindo a nova sociologia das ideias e sua transposição da abordagem de mobilização de recurso em movimentos sociais para movimentos acadêmicos/intelectuais/científicos, eu os compreendo como "esforços coletivos na busca de programas ou projetos de pesquisa para pensar em face da resistência de outros na comunidade científica ou intelectual" (Frickel \& Gross, 2005: 206).

Vindos de ângulos diferentes, ainda que complementares, os proponentes de um novo paradigma tomam posse de uma ideia (por exemplo, a abordagem relacional), de um conceito (por exemplo, mecanismo causal) ou de um tema (por exemplo, cultura ou moralidade) do interesse de vários competidores no campo. Enquanto propõem sua própria visão específica da questão, também convidam colegas a se juntar a eles, inaugurando dessa forma um subcampo cooperativo-competitivo de pesquisa para prospecção e exploração. Agressivamente conduzida por empreendedores acadêmicos, normalmente dos Estados Unidos, eles intencionam saturar a atenção, criar uma tendência e estabelecer uma escola com seus líderes e porta-vozes credenciados, redes e citações, conferências anuais, mesas-redondas, grupos de trabalho e publicação de livros, dossiês especiais de revistas e, até mesmo, novos periódicos. Isso foi o que ocorreu na Inglaterra com a filosofia analítica por volta de I920 e nos EUA com o positivismo lógico no final dos anos I930. Fundidos, aqueles movimentos deram origem à filosofia analítica, que domina agora, largamente, no mundo anglófono. Voltando ao continente, isso ocorreu na França com o existencialismo na década de I950 e com o estruturalismo na seguinte. Na Inglaterra, vimos a emergência dos cultural studies nos anos 1980. Transpostos para os EUA, eles se transformaram em pósmodernismo nos anos 1980 e pós-estruturalismo nos anos I990. Desde a declaração de Richard Rorty (I967) de uma "virada linguística" na filosofia, que precedeu seu próprio passo da filosofia analítica à pragmática, foram tantas e variadas viradas, torções e retornos nas ciências humanas e nos chamados "estudos", que posso ter perdido algumas poucas. ${ }^{3}$ Agora isso está ocorrendo de novo, mas em escala menor, na sociologia.

Neste artigo, focalizarei mais atentamente a sociologia relacional a fim de verificar se ela é mais do que uma confederação de metateorias e metametodologias isoladas navegando sob bandeira única por simples conveniência. O conjunto de teorias que compõem a sociologia relacional será o objeto de minha análise - como se fosse meu "campo". Distinguirei diferentes abordagens, mapearei as principais divisões e sistematizarei as relações entre alguns de seus conceitos fundamentais. Minha questão central é se o conceito de relação é um operador mágico que pode integrar as várias abordagens dentro de uma teoria social complexa. Atualmente, a sociologia relacional é, sobretudo, um conjunto composto por afinidades eletivas. Múltiplas 
tensões, contradições e complementaridades atravessam o campo. Podem elas ser superadas? Temos que aceitar como uma questão de fato a coexistência de uma variedade de sociologias relacionais em competição? Serão elas unidas por mais que uma enfatuação com o terminus relationis?

A sociologia relacional só emergirá como uma abordagem de pleno direito com ambições paradigmáticas quando for bem-sucedida em integrar sistematicamente as várias abordagens e dimensões em uma teoria social geral. Para conduzir a tal teoria que axiomatize, sistematize e unifique a gama completa de sociologias relacionais, necessitamos definitivamente de mais síntese teórica e mais articulação entre as abordagens. Para evitar incompreensões: uma teoria social relacional geral não é uma teoria universal. Não é uma grande teoria unificada - como o funcionalismo estrutural de Parsons ou o estruturalismo funcional de Luhmann -, que propõe um quadro conceitual unificado prescrevendo os lineamentos de conceitualização e de pesquisa empírica. Não é "uma teoria para o fim de todas as teorias". De forma mais modesta, com base num mapeamento do campo das sociologias relacionais, a teoria social geral é uma tentativa para indicar os blocos elementares de construção que qualquer teoria social relacional tem pretensões sintéticas de incorporar em sua construção. Dependendo da locação de alguém no campo (se se começa, digamos, por Bourdieu, pela análise de rede ou pelo pragmatismo), os blocos conceituais (tais como campo, redes, interações, por exemplo, ou relações e processos) serão necessariamente arranjados de maneiras diferentes. Isso é como deveria ser. O ponto dessas construções não é encerrar a teorização, mas exatamente o oposto. Mediante a interarticulação sistemática dos blocos elementares de construção, o ponto é desenvolver diferentes teorias e conduzi-las ao diálogo e à comunicação, abrindo o campo para uma teorização de níveis mais altos de abstração e de articulação.

A emergência de uma teoria social relacional geral está no horizonte. Ainda não está dentro do alcance. Mais trabalho tem de ser desenvolvido. Este artigo é uma modesta contribuição para a tarefa comum. Ele é assim estruturado: inicialmente farei uma primeira exploração da sociologia relacional. Esboçarei os contornos do campo, mapearei seus principais atores e distinguirei dois polos: um relacional-estrutural e outro interacionista-processual. Em seguida, proponho considerar Karl Marx, Georg Simmel, Gabriel Tarde e Marcel Mauss os primeiros teóricos relacionais. Juntos, eles formam um sistema. Também distinguirei quatro constelações relacionais e sugerirei que uma teoria social relacional precisa entrelaçar estruturalismo, processualismo, interacionismo e simbolismo. Na última parte, defenderei a ideia de que a sociologia relacional geral precisa ser sintética e farei uma primeira articulação entre estrutura, cultura e práticas. ${ }^{4} \mathrm{~A}$ síntese que proponho é altamente sugestiva. Duvido de que ela seja satisfatória. A principal mensagem de meu texto é, portanto, transpessoal. A fragmentação da sociologia 
relacional só pode ser superada em uma teoria social relacional geral. Essa é uma árdua tarefa e, também, coletiva.

\section{A REDE RELACIONAL}

Não estou certo de que a sociologia relacional seja um paradigma. Sem consenso sobre os fundamentos ontológicos, as premissas epistemológicas ou os adereços metodológicos adequados, eu a vejo mais como uma "virada" (mais uma após as viradas linguística, cultural, interpretativa, narrativa, reflexiva, performativa, ontológica) do que como uma "mudança" paradigmática (Cantó-Milà, 20I6: I2). Tal como as outras viradas que a precederam, essa também foi conduzida pela teoria. Começando na sociologia, ela tem o potencial de transbordar para as disciplinas vizinhas e se tornar multi-, intere, talvez mesmo, transdisciplinar. ${ }^{5}$ Tal como as demais, a virada relacional tem sido bem-sucedida ao transformar um "tópico" de pesquisa em um "recurso" para teorização. O que era um objeto de investigação foi deslocado para uma perspectiva geral sobre o mundo (coisas, pessoas e conceitos). O objeto tornou-se um projeto. Em termos sistêmicos, esse deslocamento do objeto de análise para uma perspectiva geral corresponde à transformação de uma "ordem primeira" em uma "ordem segunda" de observação (Fuchs, 200I). O "o que" (a relação) foi transmutado em "como" (a perspectiva relacional): o que no início era visto torna-se, então, um modo de ver. Substâncias se dissolvem em relações e processos. Para onde quer que se olhe, veem-se relações, redes e interações. ${ }^{6}$

A sociologia relacional transformou um manifesto relacional (Emirbayer, I997) em um programa de pesquisa, e um programa de pesquisa em um movimento acadêmico dentro das ciências sociais. Sendo uma carreta que é empurrada, promovida e coordenada por sociólogos canadenses (Dépelteau \& Powell, 20ı3; Powell \& Dépelteau 2013), a sociologia relacional não é um paradigma, mas sim um conjunto difuso de teorias com afinidades (s)eletivas que são inspiradas por trabalhos de Harrison White (análise de rede), Norbert Elias (sociologia figuracional), Pierre Bourdieu (sociologia crítica), John Dewey (pragmatismo), Niklas Luhmann (teoria dos sistemas) ou Bruno Latour (teoria do ator-rede). Quem quer que se tenha inteirado da sociologia relacional terá notado que ela funde duas diferentes abordagens, uma relacional e outra processual, em apenas uma, sob uma simples bandeira de conveniência. A virada - se o for - é uma virada hifenizada. A unidade do rótulo não deveria esconder a polaridade entre seus extremos estruturalista-relacional e pragmatista-processual.7 O violento confronto entre "relacionistas processuais" e "realistas relacionais" (Donati \& Archer, 20I5) não é apenas sobre o estatuto ontológico da emergência. Ele opõe radicalmente diferentes visões de estrutura e processo, estrutura e agência, modernidade e subjetividade (Sawyer, 2002). À medida que se move de um polo a outro, passa-se de uma proposta 
mais realista a uma mais construtivista. Dentro do movimento, diferentes vertentes podem ser reconhecidas. Aqui eu apenas as mencionarei, ordenando-as ao longo de uma escala de realismo/construtivismo.

No polo estruturalista, encontramos a Escola de Nova York de analistas de rede que seguem as trilhas de Harrison White e Charles Tilly (Mische, 20II).$^{8}$ Dentro da rede, encontramos teóricos como Mustafa Emirbayer, Margaret Somers, Sidney Tarrow, Peter Bearman e Barry Wellman. Algumas vezes, eles se unem às equipes dos sociólogos "figuracionais" e dos bourdieusianos. Entre os teóricos nessa linha, encontramos Benjo Maso, Johan Heilbron, Bernard Lahire, Louis Pinto, Rogers Brubaker e Nick Crossley. A sociologia crítica de Bourdieu pode também casar-se com o realismo crítico de Roy Bhaskar. Esse é definitivamente o caso dos realistas americanos, como Philip Gorski, Georg Steinmetz e Keith Sawyer, embora Margaret Archer, Pierpaolo Donati e Doug Porpora se tenham oposto fortemente ao legado bourdieusiano e criado um realismo crítico relacional como uma dissidência dentro do movimento realista. Pierpaolo Donati, que desde os anos 1980 vem desenvolvendo sua própria escola de sociologia relacional em Bolonha (Donati, I99I), é fortemente influenciado pelo funcionalismo. Ele é um realista, ao passo que os luhmanianos, como Günter Dux, Stephan Fuchs e Jan Fuchse, constroem sobre a cibernética de segunda ordem para introduzir uma forte flexão construtivista dentro do funcionalismo, levando o funcionalismo estrutural de Parsons na direção de uma teoria da complexidade construtivista radical.

No polo mais construtivista-processual do espectro, encontramos um grupo completo de autores que incorporaram o ducto pragmatista e se recusaram a reconhecer a existência de níveis sociais, o fenômeno de emergência e o dualismo entre agência e estrutura por ele acarretado. ${ }^{9}$ Algumas vezes eles constroem sobre uma leitura pragmatista de Elias (I97I) (especialmente Was ist Soziologie?) a fim de propor uma concepção radicalmente processual de sociedade. François Dépelteau, Andreas Glaeser, Andrew Abbott, Peter Selg, Osmo Kivinen e Tero Piiroinen defendem uma posição pragmatista, mas, em seu radicalismo, eles já incorporaram a ontologia neovitalista de Deleuze e Latour. Com seu foco sobre associações sociotécnicas entre humanos e não humanos, a teoria do ator-rede tem sabor fortemente relacional e processual. Além e contra todos os durkheimianos, de Bachelard a Lévi-Strauss e Bourdieu, ela propõe uma "ontologia plana" em que tudo está em fluxo e é eminentemente conectável. De modo paradoxal, com sua insistência sobre fluxos, associações, relações e práticas, ela se une ao anti-humanismo dos estruturalistas, mas agora no nível molecular.

A sociologia relacional foca em todos os tipos de relações possíveis e transforma esse foco em tripla lente que refrata os níveis ontológico, epistemológico e metodológico de análise em um único focus imaginarius. No nível ontológico, ela assume que as relações essencialmente criam a vida social. 
No início era a relação e na relação está o início. ${ }^{\text {Io }}$ Além e contra as abordagens holistas e individualistas, ela afirma a primazia das relações. Nem o indivíduo nem a sociedade existem por si mesmos - salvo por implicação mútua. Faz as relações entre pessoas precederem os indivíduos, e, mais, a própria sociedade é em última instância um complexo relacional que emerge das transações entre pessoas forjando redes, campos, figurações, estruturas, sistemas, instituições e outras formações. No nível epistemológico, a sociologia relacional opõe o pensamento categorial das abordagens substancialista, subjetivista e essencialista ao pensamento relacional das abordagens estruturalista, processual e interacionista. O desafio é sempre transformar qualquer abordagem rival (escolha racional, funcionalismo, sociologia cultural) ou conceito (poder, identidade, função) e reformular suas categorias em termos processuais, transacionais e relacionais. É, contudo, mais do que um exercício de tradução; é uma conversão a outra visão de mundo e um convite para ver o próprio mundo como um tecido de interações, transações e processos. No nível metodológico, a sociologia relacional substitui as técnicas lineares de correlação entre variáveis dependentes e independentes pelas técnicas mais complexas que são capazes de apreender e representar as múltiplas inter-relações entre pessoas, grupos e instituições. Em vez de trabalhar com um modelo linear geral que assume "que o mundo social consiste em entidades fixas com atributos estáveis, que aqueles atributos têm apenas um significado causal ao mesmo tempo; que esse significado causal não depende de outros atributos, da sequência passada de atributos ou do contexto de outras entidades" (Abbott, 200I: 59; ver também I87-I88 e 285-288), as metodologias relacionais enfatizam a interdependência mútua das variáveis e dissolvem as entidades em processos. ${ }^{\text {II }}$ Nesse sentido, a regressão múltipla e as análises de covariação dão lugar às matrizes de rede, grafos e análises de correspondência. Diferentemente das anteriores, as últimas são realizações "fenomenotecnológicas" da visão de mundo relacional. Eventualmente, quando os níveis ontológico, epistemológico e metodológico forem sistematicamente integrados em um único focus imaginarius, a sociologia relacional emergirá como perspectiva singular e mesmo, quem sabe?, como paradigma plenamente articulado. Por ora, isso ainda não ocorreu, mas eu gostaria de sugerir que é pela realização disso que o movimento intelectual se vem (in) conscientemente empenhando.

Enquanto tentativa concertada para focar a atenção na relação - saindo de categorias e grupos delimitados para campos, redes e interações -, o Manifesto por uma Sociologia Relacional, do pragmatista-relacional Mustafa Emirbayer (I997), pode ser tomado como um importante marcador. O próprio Emirbayer nada inventou, mas, tal como comumente fazem os manifestos, ele trabalhou sobre uma variedade de autores (Cassirer, Bourdieu, Dewey) e tradições (neokantismo, pragmatismo e análise de rede), a fim de empreender um novo programa 
de pesquisa integrador e construir um novo paradigma relacional para a sociologia. Em sua elaboração de uma nova linha de fuga sobre o mundo social, ele raramente menciona quaisquer dos predecessores da filosofia. Ele poderia ter invocado a ontologia do processo de Heráclito, o nominalismo antiescolástico da Idade Média, a teoria perspectivista de Nicolau de Cusa, a concepção relacional do tempo e do espaço de Leibniz, o conceito de interação e de comunidade de Kant, a dialética de Hegel, o materialismo histórico de Marx, o vitalismo de Nietzsche, a filosofia do processo de Whitehead... Deixando de lado o prazer pelo pedantismo e pela erudição, não há qualquer necessidade de voltar a tão longe. Não que esses não sejam predecessores possíveis para o interesse pelo relacionismo sociológico de hoje, mas as ligações são mais próximas. Não existe qualquer interesse em invocar uma linha de filósofos ilustres que os sociólogos não leram. Se eu tivesse de esquematizar as linhagens de modo a chegar a uma genealogia operacional para os teóricos sociais, eu me guiaria, a título de esboço, por quatro nomes: Karl Marx, Georg Simmel, Gabriel Tarde e Marcel Mauss, a fim de sugerir que, de um modo ou de outro, todas as teorizações de hoje poderiam ser reconstruídas como diferentes variações, misturas e permutações do quarteto relacional. ${ }^{12}$

\section{QUARTETO RELACIONAL}

Karl Marx: é, obviamente, fonte importante para qualquer teórico que deseje dissolver entidades e substâncias em relações e processos. Não foi ele quem afirmou que "a sociedade não é constituída por indivíduos, mas expressa a soma das inter-relações, as relações dentro das quais esses indivíduos permanecem" (Marx, I953: I76)? Pode-se facilmente apresentar passagens similares de A ideologia alemã ou da introdução de 1859 à Contribuição à crítica da economia política. A que eu escolheria como referência obrigatória vem de 0 Capital [Das Kapital], capítulo I, seção 4, "Fetichismo das mercadorias e seu segredo" (Marx, I966: 85-98), aliás, um dos textos mais especulativos de toda a obra de Marx. A frase central, que Georg Lukács (I968) mais tarde desenvolveria no sentido de uma completa teoria da reificação, é a seguinte: "[no capitalismo], uma relação social determinada entre as pessoas aparece na forma fantasmagórica de uma relação entre coisas" (Marx, 1966: 86).13 Um exemplo simples - que extraí das referências de Recherches dialectiques, de Lucien Goldmann (I959: 78), e que me ajudou há tantos anos a decifrar o hieróglifo das mercadorias como holograma dinâmico ou holograma de relações sociais - servirá para revelar o poder da dialética de Marx. "Este par de sapatos custa 5.000 francos." A frase expressa as relações sociais entre um fazendeiro, um curtidor, um sapateiro, um comerciante, seus funcionários e consumidores. Nenhuma dessas relações é visível; no entanto, seu trabalho está materializado nos sapatos, e seu valor é expresso no preço. Se introduzir a luta de classes na imagem, você pode tornar as relações dinâmicas e inseri-las em uma filosofia dialética da história que arremessa produtores 
contra proprietários em uma luta de classes contínua. Isto é exatamente o que uma "crítica desfetichizante" (Benhabib, I986: 44-69) deveria fazer: transformar os fatos sociais em relações sociais e substituir as relações sociais por uma sequência dialética de processos que fazem o mundo avançar para seu destino - a sociedade comunista na qual as relações entre as pessoas serão diretas, transparentes e sem mediação.

Georg Simmel: trata-se da segunda fonte que qualquer um dos relacionistas que se respeite teria que referir. A exposição mais sistemática de sua cosmovisão relativista encontra-se no final do primeiro capítulo de sua Filosofia do dinheiro [Philosophie des Geldes] (Simmel, I989: 55-92). Para ele, o relativismo não é uma doutrina negativa, mas eminentemente positiva. Todo e qualquer elemento do mundo pode ser analisado e unificado em uma forma simbólica, como ciência, religião, arte ou filosofia - para mencionar as principais formas em que trabalhou. Da mesma maneira, uma forma simbólica pode reunir e unificar a totalidade das coisas no mundo. Mediante multiplicação sistemática de perspectivas, o mundo pode ser analisado a partir de vários ângulos, cada um permitindo uma unificação da multiplicidade de relações de forma sintética. A integração das formas em uma polifonia delas não é relativista, mas relacionista. No final, como em Leibniz, a totalidade das perspectivas sobre o mundo é supostamente idêntica ao próprio mundo. Como tudo está interligado e forma uma unidade, pode-se juntar qualquer ponto do mundo com qualquer outro ponto. O pensamento é a operação que conecta, relaciona e integra os fragmentos do mundo em um cosmo. A unidade do mundo não é, portanto, substantiva, mas estrutural, funcional e processual.

Em "O problema da sociologia", o capítulo de abertura de sua grande Sociologia. Investigação sobre a construção de formas sociais [Soziologie. Untersuchungen über die formen der Vergesellschaftung], Simmel (1992: 13-62) aplica sua perspectiva relacionista para definir a sociologia como ciência especializada que não analisa a sociedade como tal, mas sim as formas de associação (Vergesellschaftung). Embora a noção de forma seja tipicamente kantiana e se refira a categorias compartilhadas que configuram interações e possibilitam sua coordenação, a noção de associação é de origem vitalista e se refere a uma multidão de ações recíprocas (Wechselwirkungen) que são o substrato vivo da sociedade. O ponto importante a sublinhar aqui é que os indivíduos estão conscientemente interligados por meio de formas simbólicas que estruturam os processos de interação a partir de dentro. A noção de forma é simbólica, enquanto o conceito de interação é processual. Qualquer sociologia interacionista que dissolva as formações sociais em sequências de ações concertadas e foque em ordens de interação, seja com Goffman, Elias, a Escola de Chicago ou a Escola de análise de rede de Nova York, está em dívida com a sociologia formal de Simmel.

Gabriel Tarde: não entrou, ao contrário de Simmel, no panteão dos pais fundadores da sociologia. Demasiado especulativo para a disciplina, sua so- 
ciologia universal queria capturar interações, fluxos e ondas no nível molecular. Como principal concorrente e adversário de Durkheim, Tarde (I999) inverte a primeira regra do método sociológico. Em vez de recomendar que se tratem os fatos sociais como coisas, em seu tratado de sociologia monadológica ele simplesmente afirma: "Toda coisa é uma sociedade, cada fenômeno é um fato social" (58). O que aparece como uma entidade individual é, de fato, uma sociedade composta de elementos que interagem. Para onde quer que se olhe, encontram-se inter- e intrarrelações entre fenômenos micro ou, mesmo, nanossociológicos. No nível infinitesimal, tudo é dissolvido em uma miríade de átomos interagindo e espiritualizados, cada um dos quais segue sua própria enteléquia. No geral, eles formam uma espécie de associação. A coordenação da ação em um todo não ocorre pela representação do todo em cada um dos elementos, mas por imitação, simpatia e difusão. Não há emergência no nível coletivo, mas covibração do desejo e das crenças. O coletivo existe em plano único - o "plano de consistência ou imanência", caro aos deleuzianos, negrianos e latourianos. A complexidade aumenta ainda mais por meio da diferenciação, que segue todo o caminho para baixo, não para cima. Ela difrata em meio ao espaço e preenche cada senda no universo. $\mathrm{Pa}$ ra onde quer que se olhe - nas células, nas sociedades ou nas estrelas - encontram-se apenas turbilhões, expansões e difrações de diferenças que ressoam, se comunicam e se inter-relacionam por meio de repetição, oposição e adaptação. Tarde exerceu grande influência sobre Deleuze e, pela teoria do ator-rede de Latour, eventualmente voltou à sociologia como uma ciência de associações heterogêneas que não precisam mais do conceito de sociedade. ${ }^{\mathrm{I}}$

Marcel Mauss: está no leme da sociologia relacional. Durkheim sempre se queixou de que seu sobrinho nunca terminou seus livros, mas se ele agora é lembrado como uma das figuras fundadoras da antropologia, é devido a seu famoso Ensaio sobre a dádiva (Mauss, I950), precursor tanto da antropologia estruturalista de Lévi-Strauss (I950) quanto da sociologia antiutilitarista de Alain Caillé (2007). No núcleo do ensaio está a descoberta da reciprocidade como motor da sociedade. Em todas as sociedades, desde a primitiva até a hipermoderna, a sociedade é entendida e realizada como uma rede de solidariedade e de rivalidade interpessoal e intergrupal que é mantida unida por relações obrigatórias de reciprocidade instauradas pela dádiva. A obrigação de dar, aceitar o presente e o retribuir é universal. O que explica o ciclo de dar é o espírito do doador que adere ao objeto e circula entre os sujeitos. Mauss inverte Marx e mostra que as relações entre as coisas são sempre relações entre espíritos e pessoas. As relações entre pessoas, espíritos e coisas podem ser analisadas estruturalmente como um sistema objetivo de representações pelas quais as pessoas (indivíduos e grupos) estão inconscientemente interligadas entre si ou podem ser entendidas fenomenologicamente como um sistema intersubjetivo de cooperação e rivalidade entre pessoas 
que estão conscientemente envolvidas em uma luta pelo reconhecimento. Segundo Mauss, a reciprocidade é a rocha sobre a qual a solidariedade é construída. Isso não é só verdade para as tradicionais, mas também para sociedades complexas. Ausente a rocha, as sociedades contratam relações anônimas entre funções que são impulsionadas pelo poder e pelo interesse.

\section{O QUADRANGULAR CONSTELACIONAL}

Os clássicos oferecem muitas variações em um topo clássico: não trate fatos sociais como coisas. Faça exatamente o contrário. Trate as coisas como fatos sociais e fatos sociais como relações, processos, práticas. ${ }^{15}$ As variações do aforismo de Durkheim são múltiplas e podem ser combinadas e recombinadas de diferentes maneiras. Marx, Simmel, Tarde e Mauss são concebidos aqui não como figuras permanentes, mas como uma reserva de motivos relacionais que podem ser reunidos e agregados em diferentes sociologias relacionais. Se permitimos infiltrações da filosofia, as variações são quase infinitas, mas com boa vontade elas podem ser reduzidas a quatro grandes constelações: estruturalismo, processualismo, interacionismo e simbolismo. Juntos, eles constituem um quadrangular constelacional que forma um sistema.

Estruturalismo: pela combinação de Marx, Simmel e Mauss, chegamos ao estruturalismo de Claude Lévi-Strauss, Norbert Elias e Pierre Bourdieu. ${ }^{16}$ A figura crucial e mediadora aqui é Ernst Cassirer, ex-aluno de Simmel, lido e estudado intensamente por Mauss, Lévi-Strauss, Elias e Bourdieu. Um de seus primeiros livros, Substanzbegriff und Funktionsbegriff [Os conceitos de substância e função] (Cassirer, I994), é um tratado protoestruturalista da Escola Neo-kantiana de Baden. Em síntese magistral de avanços da matemática, das ciências e da linguística, ele confirma o prognóstico de Simmel de que, como as artes modernas, as ciências modernas estão cada vez mais dissolvendo substâncias em funções e relações. Elas substituem a lógica aristotélica de categorias e substâncias por uma lógica relacional de funções e campos em que as substâncias são reconstruídas enquanto instâncias particulares e concreções de funções matemáticas. A própria natureza dos elementos não é determinada por suas substâncias ou sua essência, mas sobredeterminada por sua posição em um campo, configuração ou sistema de relações. Dentro da sociologia, a concepção do campo de Bourdieu, com sua cascata causal fortemente integrada de relações internas entre posições objetivas, disposições incorporadas e posicionamentos públicos, é a concretização mais desenvolvida e mais conhecida das lógicas relacionais.

Processualismo: mediante a combinação de Simmel, Tarde e Mauss, passamos de um estruturalismo relacional para uma sociologia dinâmica, processual e ondulatória de associações sem emergências. Os sociólogos processuais partem da premissa de que o mundo social está em constante mudança. Tudo flui. A estabilidade não é dada. A ordem social deve, portanto, 
ser explicada. Enquanto o polo estruturalista da sociologia relacional reconhece o fenômeno da emergência, seu polo processual enfatiza o de "desemergência”. Contra toda forma de dualismo, seja analítica ou empírica, epistemológica ou ontológica, essa sociologia defende uma ontologia radicalmente processual e uma praxeologia concomitante. Nessa visão processual, não há estruturas, não há nenhum sistema, nenhum nível, nem estratos. A realidade não é estratificada (como em Bhaskar), mas plana (como em Deleuze) e fluida (como em Dewey). Em vez do dualismo e da descontinuidade, obtemos sinequismo e continuidade. ${ }^{17}$ A sociedade e o indivíduo não são instâncias diferentes, mas modulações dentro de um único processo de estruturação sem fim. De modo relutante, a existência de cristalizações temporárias é concedida, mas não há alienações ou reificações. No fundo, há apenas fluxos e processos de devir, apenas inter- e intrarrelações em um nível horizontal, apenas re- e desestruturações contínuas da sociedade.

Interacionismo: a combinação de Simmel, Mead e Mauss traz de volta para o centro da sociologia a relação interpessoal entre eu e tu (Buber) ou ego e alter (Parsons): "No início era a relação". ${ }^{18}$ Enquanto o processualismo radical entra em direção anti- e, possivelmente, pós-humanista de uma teoria das práticas anônimas sem sujeito e sem simbolismo, o interacionismo concebe a sociologia como uma teoria da ação consciente e intencional nos níveis individual e coletivo. Do ponto de vista interacional, a sociedade não é constituída por relações. Ela não tem "relações"; como bem disse Donati (2015: 2), ela "é relação" - uma relação entre pessoas, mediada pela cultura. Como um círculo de sociabilidade que vai da família e dos pares às aldeias, das nações e da comunidade internacional ao mundo, a sociedade é uma comunidade com geometria variável. Estendendo a insistência de Buber sobre o "eu" e o "tu" a toda a gama de pronomes pessoais, Norbert Elias (I97I: I39) sugere que concebamos a sociedade como "pessoas no plural" e analisemos sua teia das interdependências da perspectiva de cada um dos pronomes pessoais. "Nós não podemos imaginar um 'eu' sem um 'você', um 'ele' ou uma 'ela' sem um 'nós', um 'você' ou um 'eles'” (I36). As posições do sujeito são sistematicamente inter-relacionadas em uma configuração. Por meio de uma troca sistemática de perspectivas, a sociedade pode ser entendida como a integralidade de todas as perspectivas inter-relacionadas. Embora Elias tenha uma teoria dos símbolos, o simbólico de algum modo lhe escapa em sua descrição das figurações inter-humanas. ${ }^{19}$ Como em uma dança, as pessoas são interdependentes e se movem ao longo do tempo e do espaço. Elas se dão as mãos, mas dificilmente se falam.

Simbolismo: na antropologia, o simbolismo é tópico central. Na sociologia, preferimos falar em cultura. Geralmente invocamos as sociologias interpretativas de Max Weber, Alfred Schütz e George Herbert Mead para defender a posição do interacionismo simbólico (entendido de modo amplo). Como penso que podemos chegar a posições semelhantes por meio de uma articula- 
ção entre Simmel (I996) (seus ensaios sobre Verstehen e a filosofia da história) e Mauss (sua teoria das representações simbólicas corrigindo a teoria das representações sociais de Durkheim), eu não preciso trazer outros autores para mostrar que a relação entre indivíduos não é diádica e direta. As relações entre as pessoas são sempre mediadas por uma representação simbólica de sua unidade e de sua diferença. Em linguagem à moda antiga, poder-se-ia dizer que a relação entre almas ocorre no e pelo espírito. Para pensar a mediação simbólica pela cultura (Kant), linguagem (Humboldt) ou história (Dilthey), diferentes maneiras estão abertas. De um jeito ou de outro, todas convergem na posição sintética do "neokantianismo pós-hegeliano". Uma vez que se trata de uma filosofia de formas simbólicas e formações culturais, trata-se de uma posição neokantiana; e, à medida que as formas simbólicas evoluem em uma fenomenologia histórica do espírito, trata-se de posição hegeliana. Uma vez que o espírito absoluto colapsa no espírito objetivo, o neokantianismo pós-hegeliano coincide com uma sociologia cultural que destaca o papel do simbólico na configuração das ações, da coordenação das interações e da constituição da sociedade. É graças à mediação de símbolos que os atores podem trocar posições, assumir os papéis uns dos outros e coordenar seus respectivos papéis dentro da configuração que, juntos, eles estabelecem. O domínio do simbólico precede, medeia e executa as interações. Ao estruturar os significados que os atores dão à sua ação "de dentro", integra-os em uma comunidade social de sentidos, normas e valores compartilhados. Graças à comunicação, os atores podem agir em comum e formar um tipo de "subjetividade coletiva" (Vandenberghe, 2010: 212-257).

\section{AÇÃO E ESTRUTURA COMO PROCESSO}

Uma teoria social geral das relações deve ser capaz de entrelaçar os vários motivos que se encontram em Marx, Simmel, Tarde e Mauss em uma tapeçaria coerente do mundo social. Para ser plural e sintética, ela tem que ser, ao mesmo tempo, completamente estruturalista, figuracional, processual, interacionista e simbólica. De uma forma ou de outra, precisa integrar ("relacionar") duas ordens de realidade: a rede de relações objetivas entre posições ("integração sistêmica") e a rede de relações subjetivas entre pessoas ("integração social”). ${ }^{20}$ Como as duas ordens da realidade só podem ser integradas por mediação da cultura, a articulação entre posições e pessoas, estruturas e interações, redes e comunicações pressupõe, na minha opinião (Vandenberghe, 20I6), maior articulação entre cultura e práticas. No nível metateórico, pode-se dizer que uma teoria social geral precisa analisar e articular sistematicamente os conceitos de estrutura social, cultura e prática em um quadro coerente (Kögler, I997). Uma vez ausente um dos blocos de construção aludidos, a construção relacional torna-se instável. Sem um conceito sólido de estrutura e sistemas sociais, a teoria social torna-se idealista 
e perde sua vantagem crítica (como é o caso da teoria da estruturação de Giddens). Sem concepção adequada de cultura e simbolismo, ela se torna mecanicista e determinista (como é o caso de Althusser e da network analysis). Sem uma teoria convincente das práticas, as estruturas sociais e culturais são reificadas em processos anônimos sem sujeitos (como é o caso da teoria do ator-rede e da teoria das assemblages).

A ordem simbólica vem em primeiro lugar. Isso já é sempre pressuposto. Forma o pano de fundo das práticas, que estrutura as práticas "de dentro", conectando-as virtualmente a todas as outras práticas e, assim, torna possível a constituição da sociedade. Graças à mediação da cultura, podemos repensar a relação entre agência e estrutura. Dado o seu ponto de partida, uma teoria social relacional não pode descambar para formulações individualistas ou holísticas. Tanto o indivíduo como a sociedade são "semirreais" em sua separação. Harrison White (I992: 5) apontou o modo como eles se espelham uns nos outros e formam complexa ilusão: "Essa miragem da pessoa como átomo produz miragem inversa da sociedade como entidade". Cada um é um complexo relacional em si mesmo; por meio de sua implicação mútua e graças à mediação da cultura, ambos, indivíduo e sociedade, são coproduzidos e coconstituídos em processos e práticas sociais. A sociologia relacional precisa retrabalhar as questões que estavam no centro do debate agência e estrutura, e sistematicamente reformulá-las em termos culturais e relacionais - naqueles porque a cultura é o que mantém as práticas em funcionamento, é uma fonte de ordem e mudança social; estes significam sem nenhuma das reificações conceituais que deram lugar às abordagens substantivistas e categóricas. E sem transformar a relação em outra substância. Independentemente dos conceitos que se utilizem, indivíduo e sociedade devem aparecer como cristalizações temporárias de relações, interações e processos.

A sociologia relacional não nega o fenômeno da emergência. Como Nietzsche o sabia, emergentismo, relacionismo e o processualismo são compatíveis: "O fato de uma coisa se dissolver nas relações não prova nada contra sua realidade" (apud Baum, 200I: 6or). De fato, do ponto de vista de uma teoria relacional da emergência, qualquer tentativa de eliminar as entidades com o pretexto de que elas são, em última análise, constituídas por relações entre entidades de nível inferior obscurece a natureza da emergência (Elder-Vass, 2010: 13-39). Para que uma entidade tenha propriedades emergentes, ela deve, antes de tudo, existir. A emergência ocorre em razão da estrutura de relações que mantém entre as partes que compõem um todo. A emergência é um fenômeno de composição. As próprias partes são geralmente constituídas por relações, mas é a estrutura das relações sincrônicas entre as relações que explica as propriedades emergentes e os poderes causais das entidades envolvidas. A conclusão a partir disso é que existem vários níveis, estratos ou escalas de existência e que não são evidentes os níveis que os sociólogos poderiam eliminar com se- 
gurança sem suprimir nem eliminar sua própria disciplina. O reducionismo, na verdade, é uma tendência escorregadia...

O ponto que eu quero enfatizar, no entanto, não é o surgimento das estruturas sociais, mas as suas reificação, alienação e dominação, que pressupõem a existência de entidades sociais. A sociologia relacional não precisa ignorar a existência de estruturas sociais alienadas que estão fora de controle. Essas são como "ondas estacionárias" (Abbott, 200I: 263) - processos humanos, pseudonaturais, semelhantes ao tsunami, que provavelmente engolfarão seus produtores se não forem controlados. No fundo, essas cristalizações e reificações são processos humanos; por outro lado, são também estruturas desumanas que seguem suas próprias leis e têm suas próprias dinâmicas. Precisamente porque elas são ameaçadoras e alienantes, precisamos ser capazes de conceitualizá-las tanto como estrutura quanto como processo. Como estrutura porque, se negarmos sua existência, não poderemos investigar adequadamente a inércia, os mecanismos, as operações, a ameaça que representam para a existência humana. E como processo porque se quisermos mudar seu curso, encaminhá-las e redirecioná-las, precisaremos nos lembrar continuamente de que elas só persistem quando são reproduzidas continuamente ou, para dar um tom mais militante, se as deixarmos reproduzir-se sem tentar ativamente transformá-las.

Uma teoria relacional deve ser capaz de reconhecer que a sociedade é um sistema estrutural de relações entre posições sociais, papéis e status. Tal reconhecimento pressupõe emergência e dualismo; mas o dualismo e a emergência não pressupõem necessariamente a reificação e a hipóstase do sistema. A autonomia do sistema não é absoluta, mas relativa e relacional. Isso pressupõe e depende de práticas, que dependem, por sua vez, da cultura para sua coordenação. É aí que entram os momentos processuais e genéticos. As estruturas são sempre o resultado de práticas sociais. Para analisar a sociedade, é preciso fazer uma mudança de perspectiva e conceber a sociedade de forma dupla (e talvez até mesmo de forma "não dual"). O que aparece como uma partícula sólida também é uma onda. Da mesma forma, e essa é uma das coisas que aprendi com o pragmatismo, a estrutura também é processo.

A distinção entre estrutura e processo é temporal: o passado versus o presente; a longa duração do tempo institucional e o curto tempo das interações entre pessoas. Estrutura e processo, sistema e evento, Braudel e Goffman precisam ser integrados, é claro. Essa foi uma das intuições centrais da teoria da estruturação de Anthony Giddens (I984). Contudo, se não queremos permanecer presos a um debate estéril entre agência e estrutura, precisamos reformular sua teoria em termos relacionais. A compactação da estrutura no processo demanda a mediação entre cultura e prática. Estrutura é processo, e processo é prática (processo-em-prática). As práticas são estruturadas, o que significa que elas são reguladas pela cultura e reproduzem e 
transformam estruturas sociais. A referência à cultura é essencial, porque, graças à cultura, as relações entre as pessoas se tornam interações simbólicas. Via interações, as pessoas formam redes. Tanto as interações como as redes são reguladas por estruturas sociais e culturais, que são constituídas por relações geradas por ações e interações situadas. As ações e interações ocorrem em situação. Produzem, reproduzem ou transformam as estruturas, que podem ser mais rígidas ou mais fluidas; em ambos os casos, porém, elas são produzidas como fluidificadas ou enrijecidas, sistema ou processo, por meio de práticas. Dependendo das práticas epistêmicas do analista, as práticas ordinárias dos atores são consideradas produtoras ou derivadas de estruturas. Por conseguinte, obtemos os loops da teoria da estruturação, com sua múltipla hermenêutica, mas, ao reconhecer a emergência e o dualismo, também superamos algumas de suas deficiências. Por razões políticas, agora argumentarei que o estruturalismo e o processualismo são necessários e complementares. Para mudar o mundo, temos que saber quais são as estruturas e como funcionam; e - sinal dos tempos (!) -, para não desesperar, também precisamos entender essas mesmas estruturas como processos que podem ser canalizados, redirecionados e alterados.

\section{DA ONTOLOGIA À COMPLEXIDADE}

Na tradição filosófica (Eisler, I904), a relação sempre foi concebida como um vínculo entre elementos relacionados (a relata ou relativa). O vínculo geralmente implica a ativação de três operadores: um sujeito que concebe a unidade entre os elementos (subjectum relationis), a base que justifica a relação (fundamentum relationis) e os elementos conectados (terminus relationis). A questão que desde sempre divide os filósofos é quanto ao fato de as relações serem subjetivas e imaginárias (relationes rationis) ou objetivas e reais (relationes reales). Essa oposição tradicional entre realistas (que enfatizam a existência extramental e cósmica da relação) e nominalistas (que pensam que as relações só existem na mente do observador) encontra suas repercussões nas oposições que têm atormentado a sociologia também desde sempre (micro x macro, estrutura x agência, etc.). Agora, reaparecem mais uma vez na sociologia relacional como uma série de contraposições entre realistas e construtivistas, estruturalistas e interacionistas, emergentistas e processualistas. Como tal, esse debate não pode ser facilmente resolvido. Podemos tentar mexer um pouco e brincar com conceitos - como fiz em uma tentativa de articular estrutura e processo, bem como cultura e agência em uma teoria relacional da "estrutur/(a)/ção". Meu sentimento, no entanto, é de que qualquer recombinação acabará forçosamente numa posição instável. Estamos girando em círculos e reinventando a roda. Talvez, precisemos deslocar o debate e introduzir na teoria um mínimo de teoria da complexidade para produzir algum desvio - o clinamen que altera o curso da história. 
Dever-se-ia começar com processos e práticas para em seguida avançar na direção das estruturas e sistemas? Ou dever-se-ia tentar dissolver os últimos nos primeiros? Dever-se-ia assumir que estruturas e sistemas são mais reais do que as práticas? Ou dever-se-ia defender uma ontologia das práticas e processos? Na literatura, essas opções são tipicamente apresentadas como um jogo de soma zero: dualismo (Archer) x dualidade (Giddens), emergência (Bhaskar) x "desemergência" (Latour), realismo x reificação. ${ }^{21}$ Como realista crítico, defendi o dualismo analítico contra seus detratores; como estruturacionista, vejo o benefício de uma ontologia de práticas e o perigo da reificação; como pragmatista, vejo as atrações de uma sociologia processual. Para evitar as facilidades do ecletismo e a chantagem do antirreducionismo, deixe-me apresentar a relação epistêmica entre o sujeito e o objeto como uma relação suplementar.

Contra Giddens e Archer, mas também contra Bhaskar e Latour, quero sugerir que uma sociologia relacional geral precisa "inter-relacionar" não tanto duas ordens de relações (as relações entre sujeitos e as relações entre objetos), mas três (também a relação entre sujeito e objeto). A terceira relação é epistêmica e diz respeito à ligação entre análise e realidade ou, nos termos de Roy Bhaskar (I978: 2I-24), entre as dimensões "transitiva" e "intransitiva" do conhecimento. Antes de prosseguir com meu caso, deixe-me visualizar as dimensões em termos espaciais e sugerir que uma complexa teoria social precisa integrar três tipos de relações num tríptico bem articulado com partes móveis: uma relação horizontal entre "pessoas" que interagem entre si (o mundo da vida dos fenomenólogos); uma relação vertical entre "partes" de sistemas, flutuando acima da cabeça dos atores, construída pelo analista, condicionando as práticas dos atores (o sistema dos funcionalistas); e uma relação transversal que relaciona as construções e os conceitos do analista com os dos próprios atores, e ambos com a realidade a que se referem (a realidade da teoria da complexidade).

A divisão entre estrutural-relacionistas e processual-interacionistas é de ordem epistemológica. Ela concerne ao estado ontológico que se atribui às entidades do mundo e ao modo como essas são concebidas. Ou o analista mantém sua ontologia invariável e considera que o conhecimento da realidade deve basear-se em algum tipo de fundamentum inconcussum ou, substituindo a visão espectadora do conhecimento pela perspectiva do ator, faz variar sistematicamente os pontos de vista, multiplica as ontologias e considera que se pode fazê-lo sem compromissos ontológicos a priori. Formulada assim, a divisão corresponde mais ou menos a uma oposição entre realistas e construtivistas, com aqueles reivindicando algum acesso privilegiado à realidade e estes ao ponto de vista dos atores. Um olhar mais atento revela, no entanto, sutil mudança no debate. Na verdade, ela é notável, mas raramente foi notada: todas as partes estão agora defendendo a ontologia, mas 
contra a sociologia realista agora temos antropólogos pós-estruturalistas (como Latour, Descola e Viveiros de Castro) reivindicando uma virada ontológica e filósofos clamando por uma volta à especulação e à metafísica (Bryant, Srnicek e Harman, 20II; Charbonnier, Salmon e Skafish, 20I7). ${ }^{22}$

Neste ponto, a distinção de Roy Bhaskar (1978: 56) entre os domínios ontológicos do real, o atual e o empírico fornece um útil mapa ontológico. Para transpor o registro das ciências naturais para as ciências sociais e para conectá-lo às abordagens relacionais na sociologia, teremos necessariamente que adaptá-lo. O domínio empírico é constituído por padrões de eventos que são, direta ou indiretamente, experimentados e observados em situações experimentais. Ele corresponde a um "mundo-Tractatus" de eventos atomís ticos contingentemente conectados, caros aos positivistas, que concebem a causalidade como relações estatísticas entre variáveis independentes em um sistema artificialmente fechado. O domínio do real é separado do domínio do atual. Ao contrário dos eventos empíricos, produzidos e observados pelos cientistas em seus laboratórios, os eventos reais ocorrem na natureza. Os eventos atuais podem acontecer sem que ninguém os observe ou os experimente; são o resultado de uma variedade de mecanismos generativos que operam em diferentes níveis. O domínio do atual é, por sua vez, separado do domínio do real, em que as causas que produzem os eventos encontram-se localizadas. Bhaskar os chama de mecanismos generativos e os concebe como estruturas com poderes causais. Eles são o Santo Graal do realismo crítico, que basicamente oferece uma justificativa filosófica para a busca sistemática de mecanismos causais em todas as ciências possíveis.

Embora Bhaskar às vezes dê a impressão de que os domínios empíricos e reais não são reais, os três domínios devem ser vistos como hierarquicamente ordenados e instalados no real (ver Bhaskar, I978: 56, nota à tabela I; e Elder-Vass, 2007): o empírico é um subconjunto do real; o atual também é real, mas não necessariamente empírico; o real é obviamente real, mas não necessariamente atual ou empírico. O objetivo do mapeamento ontológico, em minha opinião, não é opor-se aos domínios, mas integrá-los e explorar articulações entre mecanismos reais, eventos reais e experiências empíricas. Embora o realismo crítico seja indubitavelmente forte nos mecanismos generativos, é relativamente fraco em suas explorações do atual e do empírico. Tende a rejeitá-los (a "falácia atualista", a "ilusão positivista"), enquanto, se entendemos que o empírico e o real se referem a diferentes níveis de realidade do mesmo mundo, podemos realmente alistá-los e usar as diferentes abordagens para tornar o realismo crítico mais forte, não mais fraco. Se somos mais dialógicos, podemos até aceitar que a fenomenologia e o pragmatismo oferecem melhores abordagens das experiências atuais do que o realismo crítico (Vandenberghe, 20I7). Sem dúvida, eles estão certos ao insistir na ideia de que, no mundo social, o real é ativado pelas práticas sociais. O real depen- 
de do atual e não pode existir sem ele - o fato de que as estruturas pressupõem práticas não significa, porém, que elas sempre sejam observadas ou experimentadas. Seja como for, com a ênfase no simbólico e nas interações, nos "significados" e nas "ações", as sociologias qualitativas têm melhor compreensão do intercâmbio humano com os objetos e sujeitos em seu ambiente do que o realismo crítico.

Se aplicarmos o mapa ontológico à sociologia relacional, com algum esforço poderemos talvez identificar os processos e práticas moleculares abaixo do nível de consciência com o domínio das experiências empíricas, as redes de interações entre pessoas e objetos com o domínio do atual ("eventos"), e os campos das relações estruturais entre posições com o domínio do real ("mecanismos"). O realismo crítico concebe a relação entre o real, o atual e o empírico como uma espécie de dedução transcendental. Se levarmos o pragmatismo a sério, também poderemos inverter a relação e analisar a forma como os processos interativos e transacionais conduzem, tanto de forma diacrônica quanto sincrônica, à cristalização de estruturas emergentes. A dialética permite ambos os movimentos, para baixo e para cima. De fato, eles se referem à mesma realidade, mas analisados agora como estrutura (realismo) ou, alternativamente, como processo (pragmatismo).

Embora eu aceite a distinção de Bhaskar entre as dimensões transitiva (ontológica) e intransitiva (epistêmica) do conhecimento, penso que o realismo, tanto em suas versões críticas quanto especulativas, geralmente deixa de lado a questão da representação. Mesmo que a dimensão ontológica não possa ser colapsada no epistêmico sem que se cometa a "falácia epistêmica" (Bhaskar, 1978: 36-38), ainda é o caso de a realidade extradiscursiva, extraepistêmica, ser representada na linguagem ou no discurso. Para transformar o debate ainda mais, quero colocar a oposição entre ontologias realistas e construtivistas em um continuum e quero fazê-lo passando do construtivismo social para o construtivismo epistêmico da teoria da complexidade (Fuchs, 200I). A partir desse ponto de vista sistêmico, o realismo só é válido no primeiro nível da observação. O mundo é o que é. Embora possa ser analisado a partir de uma variedade de perspectivas, elas não constituem o mundo, ainda que revelem diferentes aspectos dele. Argumentar contrariamente a isso é equivalente a cometer a "falácia epistêmica", a ontologia sendo colapsada em epistemologia, transformando pontos de vista epistêmicos do mesmo mundo em mundos diferentes. Se, no entanto, se introduz uma observação de segunda ordem na figura em questão, as coisas mudam, e o realismo aparece como uma metaperspectiva que mantém a ontologia estável, eliminando o processo constitutivo das práticas de representação.

Uma vez a representação aceita, pode-se investigar o processo epistêmico e analisar o realismo e o processualismo como resultantes de práticas epistêmicas: quer se analise a constituição do mundo a partir da perspectiva de uma 
ontologia de práticas, quer se o analise pela perspectiva de uma epistemologia relacional das estruturas - no entanto, não é uma ou outra posição. A fixidez do mundo não depende tanto do próprio mundo, mas varia conforme a inter-relação livre entre epistemologia e ontologia. Se a inter-relação é desautorizada, fixa-se o mundo como pressuposição (terminus a quo), mas também como um fim (terminus ad quem), resultando no mundo transcendental e empírico, pressuposto e objeto, fundo e figura. ${ }^{23}$ Se alguém permite a interação e não elimina a perspectiva processual como uma ameaça, a fixidez do mundo se torna variável. O mundo é tanto estrutura como processo - às vezes mais o primeiro, às vezes mais o último, dependendo das práticas epistêmicas autorizadas ou desautorizadas. Se os conceitos do analista são privilegiados e sua relação constitutiva com o mundo que é analisado não é explicitamente incluída no retrato, o realismo mantém sua validez. Se o privilégio epistêmico do analista é afrouxado e as práticas constitutivas dos atores são trazidas ao primeiro plano, uma realidade mais processual daí se segue, e a relação entre estrutura e processo, sistema e mundo da vida pode ser investigada como uma variável.

\section{CONCLUSÃO: RUMO A UMA TEORIA SOCIAL RELACIONAL GERAL}

Neste artigo, construí uma genealogia honorável para uma teoria relacional e sugeri que qualquer posição relacional pode ser sistematicamente derivada de quatro autores: Marx, Simmel, Tarde e Mauss. Historiadores das ideias e teóricos sociais podem querer indicar outros predecessores. Eles podem sugerir, por exemplo, que Mead, Elias ou Luhmann trazem algo para a discussão que excede o quarteto. Também argumentei que uma teoria social relacional tem de integrar as motivações do estruturalismo, do interacionismo, do processualismo e do simbolismo em uma complexa teoria relacional. Dependendo do ponto de partida e do peso que se quer dar às respectivas motivações, a teoria resultante será diferente. Na verdade, é assim que deve ser. O objetivo é não desenvolver uma teoria única a que cada um deva subscrever, mas introduzir alguns marcadores na discussão e trazer todo o debate a um nível mais alto de abstração teórica e integração conceitual.

Para mim, a questão é como podemos desenvolver uma teoria realista relacional que integre estruturas sociais (Bourdieu e realismo crítico), estruturas culturais (hermenêutica e sociologia cultural), redes (Elias e análise de rede), interações (Simmel, Goffman e Mauss) e intersubjetividade (fenomenologia e Habermas) em uma ontologia reestruturada das práticas, cultura e estrutura social. Em um nível inferior de abstração, passando da teoria social para a sociologia, a tarefa é desenvolver uma teoria coerente do mundo social que possa integrar sistematicamente os conceitos do campo (Bourdieu), redes (análise de rede e ANT), interações (pragmatismo e interacionismo simbólico) e um conceito relacional de self em um único quadro. Advindo de várias tradições no campo relacional, vários autores, especialmente Emirbayer, Crossley, Fuchs, Archer e 
Donati, estão trabalhando nisso. Tivesse mais tempo e espaço, eu olharia esses esforços e analisaria o modo como eles foram levados a bom termo nas investigações empíricas de ordens de interação, relações raciais, movimentos sociais, terceiro setor e reflexividade.

O texto que apresentei não é mais do que um trabalho propedêutico para a elaboração de uma teoria social relacional geral. Tal teoria ainda não existe, mas é a ela que os teóricos relacionais estão finalmente aspirando. Percebi que fiz uma grande volta metatéorica do campo das sociologias relacionais. E só mapeando as várias posições pode-se mover além de cada uma delas, integrando-as dialógica e dialeticamente a uma estrutura mais abrangente. Apontei uma fissura entre abordagens relacionais-estruturalistas e interacionistas-processuais e, de fato, penso que, para avançar, a sociologia relacional precisa superar essa oposição por meio do diálogo. Estou ciente das divisões dentro do campo, mas, se não queremos continuar a oposição estéril entre agência e estrutura por outros meios durante mais uma década, precisamos encontrar formas de integrar estrutura e processo, sistema e interação, micro e macro em uma teoria social relacional. Não nego que alguém possa ganhar pontos ao opor a uma posição a outra, argumentando com realistas contra as ontologias do processo, ou vice-versa, mas temo que o campo, enquanto tal, não tenha nada a ganhar com as escaramuças acadêmicas. Todos sabemos que, de uma forma ou de outra, os sociólogos relacionais precisam levar a sério as teorias de Bourdieu e Luhmann, Archer e Latour, Dewey e Elias, para citar apenas alguns dos protagonistas desse debate em andamento. Sempre podemos opor uns aos outros, mas, juntos, precisamos avançar e explorar formas alternativas de superação do impasse.

Recebido em I3/04/2017 | Aprovado em 9/7/2017

Frédéric Vandenberghe é professor de sociologia do Instituto de Estudos Sociais e Políticos da Universidade do Estado de Rio de Janeiro (Iesp/Uerj). Trabalha na área da teoria social e coordena o Sociofilo. Com Alain Caillé, publicou Pour une nouvelle sociologie classique (2016). 


\section{NOTAS}

I François Dépelteau encomendou-me este artigo para inclusão no Handbook of relational sociology (Dépelteau, no prelo). Sem ele, eu não o teria escrito. Agradeço-lhe de coração apoio, comentários e críticas. Uma primeira versão do artigo foi apresentada na conferência intermediária do GT da ISA sobre teoria sociológica, em Cambridge, em junho de 20I6, e na conferência anual da Anpocs, em Caxambu, no Brasil. Agradeço a Jeffrey Alexander, Martina Löw, Hans-Peter Müller, Gabriel Cohn e André Magnelli “o falar sobre a relação" comigo. Na publicação deste artigo, fui gentilmente instigado por Elina Pessanha e acompanhado por três tradutores cuja solidariedade agradeço: Diogo Corrêa, Alberto Luís Cordeiro de Farias e André Magnelli.

2 A "virada linguística" em filosofia é múltipla. Dependendo da tradição de onde se vem (filosofia anglo-analítica, idealismo alemão, estruturalismo francês ou pragmatismo americano), pode-se conduzir via Frege, Wittgenstein e Austin (Reino Unido), Humboldt, Heidegger e Habermas (Alemanha), Saussure, Lévi-Strauss e Derrida (França) ou Peirce, Mead e Dewey (EUA). Em Rorty, há duas viradas linguísticas: a primeira é propriamente analítica e corresponde a uma tentativa quase positivista de introduzir a análise semântica na filosofia e transformá-la em ciência. A segunda faz um amálgama de Heidegger, Wittgenstein e Dewey em crítica antifundacionista da epistemologia e crítica nominalista da ontologia. Retrospectivamente, podemos ver que a virada linguística lançou um modelo - um ensaio programático num livro organizado para anunciar enfaticamente um avanço, com uma série de capítulos que representam e realizam a virada.

3 Para uma boa visão geral de algumas das viradas nas ciências humanas, ver Bachmann-Medick (20I6) e Sussen (2015). Até agora, contei a ocorrência de cerca de 50 viradas. Bachmann-Medick também deixou escapar algumas, mas a tradução de seu livro do alemão para o inglês lhe permitiu atualizar significativamente a bibliografia.

4 A síntese metateórica de estrutura, cultura e práticas é apenas o andaime para uma articulação teórica dos conceitos de campos, redes e interações. Devido a restrições de tempo, não pude ir além da metateoria. 
5 Nós já temos psicologia relacional (incluindo a psicanálise das relações-objeto), arqueologia relacional, antropologia relacional e agora também história relacional. Com o surgimento de "histórias interconectadas" e a cascata de termos relacionais referentes, como "'intercâmbio' e 'relações sexuais', 'links' e 'enredos', 'redes' e 'fluxos'” (Conrad, 20I6: 64), os historiadores globais estão empurrando para trás: "Tudo não está ligado e conectado a tudo" (I5). A questão das inter-relações não é apenas teórica, mas empírica, sendo a interconexão variável.

6 No limite, o relacionismo corre dois riscos. O primeiro é lógico e diz respeito à transformação da relação em um sujeito ou em uma substância. A reificação da relação colapsa em sua personificação. A segunda é cosmológica. Quando tudo está relacionado a tudo e todos estão conectados a todos, a sociologia e a antropologia se encaixam em uma cosmologia: "A relação é o compromisso ideal, a palavra do diplomata. A relação é entre a sociedade, o indivíduo, a ação. Vemos as relações a cada momento. É verdade. Quando eu escrevo estas linhas, estou em relação com um leitor sobre quem eu estou pensando na esperança de que ele acompanhe meu argumento. Uso um computador, uma caneta e papel. Vejo objetos e árvores ao meu redor. Só existem relações!" (Piette, 20I4: 5-6). Inevitavelmente, surge a questão: o que não é relacional? O que resta se subtrairmos as relações? Para sair da dobra, Albert Piette propõe uma antropologia existencial que investigaria não a relação, mas um indivíduo em sua singularidade, à medida que ele/ela apareça fora do sistema, da estrutura ou da rede, isolado dos outros.

7 Como coordenador da rede de sociólogos relacionais, François Dépelteau é inclusivo e ecumênico. Quem se identifica com o projeto relacional e quer contribuir para a sua expansão está dentro da rede. Mas como autor (Dépelteau, 2008, 20I5), ele é um pouco mais divisionista e desenvolve sua sociologia transacional como uma sociologia pragmatista-processual radical sem qualquer concessão ao polo mais estruturalista da sociologia relacional.

8 Com sua forte posição anticategórica, a reconstrução de Wellmann (1988) das premissas da sociologia estrutural ainda oferece a melhor introdução à abordagem relacional da análise de rede. 
9 Para um conciso resumo-exposição dos princípios ontológicos de uma sociologia processual, ver Abbott, 2016: I-2.

Io Uma das últimas edições da Revue du Mauss (2016, I), consagrada à sociologia relacional, tem título cativante: "No início era a relação"; e uma pergunta-pancada: "Mas o que vem depois?".

I I Para uma análise brilhante da multideterminação causal, em que cada uma das variáveis funciona simultaneamente por meio de todas as outras, ver Panica Pontes (20I5).

I2 Para introduções mais filosóficas que abordam temas relacionais no quarteto, ver Ollman (I993) sobre Marx; Vandenberghe (2002) sobre Simmel; Lazzarato (2002) sobre Tarde; e Karsenti (I997) sobre Mauss. Para agradar aos americanos, eu poderia ter transformado o quarteto em um quinteto, adicionando Georg Herbert Mead. Se não o fiz é porque penso que o processualismo, o interacionis mo e o simbolismo que caracterizam seu pragmatismo podem ser obtidos pela fusão de Simmel e Mauss.

I3 Es ist nur das bestimmte gesellschaftliche Verhältnis der Menschen selbst, welches hier für sie die phantasmagorische Form eines Verhältnisses von Dingen annimmt.

I4 Via Deleuze, podemos retornar também a Spinoza e realizar uma virada afetiva a fim de teorizar e analisar a coordenação da ação nos níveis pré-subjetivo, infraconsciente e transindividual da existência (cf. Seigworth \& Gregg, 2010).

I5 A tomada etnometodológica que Melvin Pollner assume em Durkheim merece menção especial: trate os fatos sociais não como coisas (things), mas como atos (doings) ou, como ele fala, como "-ings" (Pollner, citado em Desmond, 20I4: 566), ou seja, como ações concertadas em situações concretas de ação.

I6 Meu próprio interesse pela sociologia relacional vem da exploração da genealogia intelectual que liga Simmel a Cassirer (Vandenberghe, 200I) e Cassirer a Bourdieu (Vandenberghe, 2010: 43-84).

I7 Sobre a sinecologia de Peirce, a doutrina pragmática de que tudo o que existe é contínuo, ver Not cynicism, but synechism, de Haack (2013). 
I8 "Im Anfang ist die Beziehung" (Buber, I962: 25). Como o filósofo do diálogo, Buber pensava sobretudo nas relações interpessoais, entre eu e você, o sujeito e o outro/Outro. Ele concebe a relação em termos fenomenológicos como relação intencional de consciência entre eu e você (em oposição à relação de despersonalização que liga eu a ele).

I9 Tal como George Herbert Mead, Norbert Elias é um clássico da sociologia relacional. Dependendo do que se lê, seu trabalho pode de fato ser invocado para defender sistematicamente um estruturalismo ( $O$ estabelecido e os outsiders); processualismo (O que é sociologia?); emergentismo (o pós-escrito de I968 para o Processo civilizador); e simbolismo (A teoria simbólica). O que é necessário, no entanto, e que Elias não oferece é uma teoria relacional única em que todos os elementos estejam totalmente integrados.

20 Em sua discussão sobre o tropo da rede na teoria social e na filosofia, Boltanski e Chiapello (I999: 208-230) distinguem duas vertentes principais: uma mais objetiva e estrutural, representada pelo estruturalismo, pela análise de rede e pela teoria de atores e redes, e outra mais intersubjetiva e comunicativa, idealmente representada por Habermas. As duas vertentes se unem para constituir a cité por projetos do capitalismo contemporâneo. Aqui eu quero integrar o objetivo e as abordagens intersubjetivas em uma teoria social relacional e, como Emirbayer, Mische, Goodwin, Fuhse e outros, acho que o truque é fazê-lo por meio da cultura.

2I O debate entre realistas (Bhaskar, Archer, Mouzelis) e estruturacionistas (Giddens, King, Pleasants) já se arrasta há 30 anos. Ele gerou uma indústria artesanal acadêmica (veja o conjunto em caixa de quatro volumes editados por O’Donnell, 20I0), mas não estou convencido de que as posições tenham mudado muito. O ressurgimento do pragmatismo e a introdução de ontologias processuais no debate (Kivinen \& Piiroinen, 2006; Dépelteau, 2015) não produziram avanço. Só reforçaram as posições existentes e levaram a um impasse.

22 A mudança da sociologia da ciência (STS) para uma antropologia das visões do mundo mudou repentinamente o jogo - da cultura à ontologia e, a partir daí, de volta à cultura (ver o debate em Venkatesan et al., 2010). Esse 
deslocamento tem reconfigurado o debate como aquele que opôs o realismo crítico antigo a um realismo especulativo recém-formado, mais midiático, que deve mais a Badiou, Zizek, Deleuze e Latour do que a Roy Bhaskar.

23 Para uma poderosa demonstração da circularidade que transpõe a crítica de Foucault do "duplo transcendental-empírico" para a sociologia, cf. Lacerda da Silva, 2015.

\section{REFERÊNCIAS BIBLIOGRÁFICAS}

Abbott, Andrew. (200I) [2016]. Time matters. On theory and method. In: Processual sociology. Chicago: Chicago University Press.

Alexander, Jeffrey C. (I987). O novo movimento teórico. Revista Brasileira de Ciências Sociais, 2/4, p. 5-28.

Bachmann-Medick, Doris. (2016). Cultural turns. New orientations in the study of culture. Berlin: de Gruyter.

Baum, Manfred. (200I). (Verbo): Relation. III: Neuzeit. In: Ritter, Joachim; Gründer, Karlfried \& Gabriel, Gollfried (Hgs.). Historisches Wörterbuch der Philosophie, 9. Darmstadt: Wissenschaftliche Buchgesellschaft.

Benhabib, Seyla. (I986). Critique, norm and utopia. A study of the foundations of critical theory. New York: Columbia University Press.

Bhaskar, Roy. (1978). A realist theory of science. Hemel Hempstead: Harvester Press.

Boltanski, Luc \& Chiapello, Eve. (I999). Le nouvel esprit du capitalisme. Paris: Gallimard.

Bryant, Levi; Srnicek, Nick \& Harman, Graham (eds.). (20I I). The speculative turn: continental materialism and realism. Melbourne: Re.Press.

Buber, Martin. (I962) [1923]. Ich und Du. In: Das Dialogische Prinzip. Heidelberg: Lambert.

Caillé, Alain. (2007). Anthropologie du don: le tiers paradigme. Paris: La Découverte.

Cantó-Milà, Natalia. (20I6). Mainstreaming relational sociology. Theory. The Newsletter of the Research Committee on Sociological Theory, Summer, p. I2-I5. 
Cassirer, Ernst. (I994) [I9I0]. Substanzbegriff und Funktionsbegriff. Untersuchungenüber die Grundfragen der Erkenntniskritik. Darmstadt: WBG.

Conrad, Sebastian. (2016). What is global history? Princeton: Princeton University Press.

Charbonnier, Pierre; Salmon, Gildas \& Skafish, Peter (orgs.). (2017). Comparative metaphysics. Ontology and anthropology. London: Rowman \& Littlefield.

Dépelteau, François (ed.). (no prelo). Handbook of relational sociology. New York: Palgrave.

Dépelteau, François. (20I5). Relational sociology, pragmatism, transactions and social fields. International Review of Sociology/Revue internationale de sociologie, 25/I, p. 45-64.

Dépelteau, François. (2008). Relational thinking. A critique of co-deterministic theories of structure and agency. Sociological Theory, 6/I, p. 5I-73.

Dépelteau, François \& Powell, Christopher (eds.). (2013). Applying relational sociology. Relations, networks and society. New York: Palgrave.

Desmond, Matthew. (20I4). Relational ethnography. Theory and Society, 43, p. 547-579.

Donati, Pierpaolo. (2015). Manifesto for a critical realist relational sociology. International Review of Sociology, 25/I, p. I-24.

Donati, Pierpaolo. (I99I). Teoria relazionale dela società. Milano: Franco Angeli.

Donati, Pierpaolo \& Archer, Margaret S. (20I5). The relational subject. Cambridge: Cambridge University Press.

Elias, Norbert. (I97I). Was ist Soziologie? Utrecht: Spectrum. Eisler, Robert. (I904). Verbo: Relation. In: Wörterbuch der philosophischen Begriffe, Band 2. Berlin: E.S. Mittler, p. 248-25I. Elder-Vass, Dave. (2010). The causal power of social structures. Emergence, structure and agency. Cambridge: Cambridge University Press.

Elder-Vass, Dave. (2007). Re-examining Bhaskar's three ontological domains: The lessons from emergence. In: Lawson, Clive; Latsis, John \& Martins, Nuno (eds.). Contributions to social ontology. London: Routledge, p. I60-176. 
Emirbayer, Mustafa. (1997). Manifesto for a relational sociology. American Journal of Sociology, I03/2, p. 28I-3I7.

Frickel, Scott \& Gross, Neil. (2005). A general theory of scientific/intellectual movements. American Sociological Review, 70, p. 204-232.

Fuchs, Stephan. (200I). Against essentialism. A theory of culture and society. Cambridge: Harvard University Press.

Goldmann, Lucien. (1959). Recherches dialectiques. Paris: Gallimard.

Giddens, Anthony. (1984). The constitution of society. Outline of the theory of structuration. Cambridge: Polity.

Haack, Susan. (2013). Not cynicism, but synechism: lessons from classical pragmatism. In: Putting philosophy to work. Inquiry and its place in culture. Amherst: Prometheus Books, p. 83-96.

Karsenti, Bruno. (1997). L'homme total. Sociologie, anthropologie et philosophie chez Marcel Mauss. Paris: PUF.

Kivinen, Osmo \& Piiroinen, Tero. (2006). Towards pragmatist methodological relationalism. From philosophizing sociology to sociologizing philosophy. Philosophy of the Social Sciences, 36/3, p. 303-329.

Kögler, Hans-Herbert. (I997). Reconceptualizing reflexivity. Social Epistemology, I I/2, p. 223-250.

Lacerda da Silva, Marcos Aurélio. (2015). O discurso sociológico da modernidade. Tese de Doutorado. Instituto de Estudos Sociais e Políticos/Universidade do Estado do Rio de Janeiro. Lazzarato, Maurizio. (2002). Puissance de l'invention. La psychologie economique de Gabriel Tarde contre l'economie politique. Paris: Les empêcheurs de penser en rond.

Lévi-Strauss, Claude. (I950): Introduction à l'œuvre de Marcel Mauss. In: Mauss, Marcel. Sociologie et anthropologie. Paris: PUF, p. ix-lii.

Lukács, Georg. (1968) [1923]. Die Verdinglichung und das Bewußtsein des Proletariats. In: Geschichte und Klassenbewußtsein (GesammelteSchriften, Band 2). Darmstadt: Luchterhand, p. 257-379.

Marx, Karl. (I966) [1867]. Das Kapital. Kritik der politischenÖkonomie, v. I. In: Marx-Engels Werke, v. 23. Berlin: Dietz Verlag. 
Marx, Karl. (I953) [1857-I858]. GrundrissezurKritik der politischen Ökonomie. Berlin: Dietz Verlag.

Mauss, Marcel. (1950) [1923-I924]. Essai sur le don. In: Sociologie et anthropologie. Paris: PUF, p. I43-279.

Mische, Ann. (20II). Relational sociology, culture and agency. In: The sage handbook of social network analysis. London: Sage, p. 80-97.

O'Donnell, Mike (ed.). (20I0). Structure and agency (Key Debates in Sociology Series, 4 vols.). London: Sage.

Olmann, Bertell. (1993). Dialectical investigations. London: Routledge.

Panica Pontes, Thiago. (2015). “Crescer na vida”: trajetórias de micromobilidade nos meios populares. Tese de Doutorado. Instituto de Estudos Sociais e Políticos/Universidade do Estado do Rio de Janeiro.

Piette, Albert. (20I4). Contre le relationnisme. Lettre aux anthropologues. Lormont: Le bord de l'eau.

Revue du Mauss. (20I6). Au commencement était la relation... Mais après? Paris: La Découverte.

Powell, Christopher \& Dépelteau, François (eds.). (2013). Conceptualizing relational sociology. Ontological and theoretical issues. New York: Palgrave.

Rorty, Richard (ed.). (1967). The linguistic turn: recent essays in philosophical method. Chicago: University of Chicago Press.

Sawyer, Keith. (2002). Unresolved tensions in sociocultural theory: analogies with contemporary sociological debates. Culture \& Psychology, 8/3, p. 282-305.

Seigworth, Gregory \& Gregg, Melissa (eds.). (2010). The affect theory reader. Durham: Duke University Press.

Simmel, Georg. (1992) [1908]. Soziologie. Untersuchungen über die Formen der Vergesellschaftung. In: Gesammelte Werke. Band II. Frankfurt am Main: Suhrkamp.

Simmel, Georg. (1989) [1900]. Philosophie des Geldes. In: Gesammelte Werke. Band 6. Frankfurt am Main: Suhrkamp. Sussen, Simon. (2015). The 'postmodern turn' in the social sciences. Basingstoke: Palgrave.

Tarde, Gabriel. (I999) [I895]. Monadologie et sociologie. Oeuvres de Gabriel Tarde, v. I. Paris: Les empêcheurs de penser en rond. 
Vandenberghe, Frédéric. (2017). After words: the spirit of evolution and envelopment. In: Bhaskar, Roy et al. (eds.). Metatheory for the anthropocene. Emancipatory praxis for planetary flourishings. London: Routledge.

Vandenberghe, Frédéric. (2016). Cultura e agência: a visão "de dentro". Sociologias, I8/4I, p. I30-I63.

Vandenberghe, Frédéric. (2010). Teoria social realista. Um diálogo franco-britânico. Belo Horizonte: Ed. UFMG.

Vandenberghe, Frédéric. (2002). Relativisme, relationnisme, structuralisme. Simmel Studies, I2/I, p. 4I-84.

Vandenberghe, Frédéric. (200I). From structuralism to culturalism. Ernst Cassirer's philosophy of symbolic forms. European Journal of Social Theory, 4/4, p. 479-497.

Venkatesan, Soumhya et al. (2010). Ontology is just another word for culture. Critique of Anthropology, 30/2, p. I52200.

Wellman, Barry. (1988). Structural analysis: from method and metaphor to theory and substance. In: Wellman, Barry \& Berkowitz, Stephen D. (eds.). Social structures: a network approach. Cambridge: University of Cambridge, p. I9-6I.

White, Harrison. (1992). Identity and control. A structural theory of social action. Princeton: Princeton University Press. 


\section{A RELAÇÃO COMO OPERADOR MÁGICO. SUPERANDO A DIVISÃO ENTRE SOCIOLOGIA PROCESSUAL E RELACIONAL}

Resumo

A sociologia relacional não é um paradigma, mas um conjunto temático de teorias que tomam a relação como sua categoria central. Nesse conjunto há, basicamente, as abordagens estrutural-relacional e interacionista-processual, que navegam sob uma mesma bandeira, em tensão uma com a outra. A tarefa da teoria relacional geral é unificar essas duas abordagens, muito embora nada indique que tal teoria unificada esteja ao alcance. Nesse artigo, faço um mapeamento inicial do campo. Proponho considerarmos Karl Marx, Georg Simmel, Gabriel Tarde e Marcel Mauss os primeiros teóricos relacionais e argumento que, juntos, eles formam um sistema. De modo similar, distingo quatro constelações relacionais e defendo que uma teoria social relacional precisa entrelaçar sistematicamente estruturalismo, processualismo, interacionismo e simbolismo em uma teoria geral que articule estrutura, cultura e prática.

\section{THE RELATION AS MAGICAL OPERATOR. OVERCOMING THE DIVIDE BETWEEN RELATIONAL AND PROCESSUAL SOCIOLOGY}

Relational sociology is not a paradigm, but a thematic cluster of theories that take the relation as their central category. Within the cluster, there are, basically, two approaches, a relational-structural one and a processual-interactionist one, that fly under the same flag but are in tension with each other. The task of general relational theory is to unify these two approaches, though nothing indicates that such a unified theory is at hand. In this chapter, I do some initial mapping of the field. I propose Karl Marx, Georg Simmel, Gabriel Tarde and Marcel Mauss as prime relational theorists and suggest that, together, they form a system. Similarly, I distinguish four relational constellations and argue that a relational social theory needs to systematically interweave structuralism, processualism, interactionism and symbolism into a general theory that articulates structure, culture and practices.

\section{Palavras-chave}

Sociologia relacional; estrutural-relacional; interacionista-processual; teoria social; teoria relacional geral.

\section{Keywords}

Relational sociology; processual sociology; structures; relations; social theory. 